\title{
'Living upside down': being a young carer of a parent with mental illness
}

\section{Alan Cooklin}

\begin{abstract}
SUMMARY
Most children and young people who have a parent with mental illness will not think of themselves as carers. They may think of themselves as surviving, as lonely and isolated, and of suffering all the common experiences listed in this article. Many parents with mental illness will not acknowledge that their child has become their carer rather than the converse. So many children and young people may be left vulnerable to sometimes extremely damaging and distressing situations but without a role that recognises their contribution or even commands appropriate respect. There is a danger that simply defining these children and young people as 'young carers' may provide a cloak of acceptability for allowing quite intolerable demands to be made on them. However, young carers do have some level of support in the UK in the form of young carers' groups. So, with the above provisos, that is the focus of this article.
\end{abstract}

\section{DECLARATION OF INTEREST}

None.

How children are or are not supported in their relationship with a parent with mental illness, and most specifically how they are helped to understand the parent's behaviour, can have serious consequences for the prevention or otherwise of mental illness in these children and young people later in life. This article defines some of what is known about the impacts of parental mental illness on children and young people, their responses and what they say they need and want from professional services, as well as some suggestions for how professionals may respond.

\section{Background to the problem}

\section{England and Wales}

Extrapolation from the studies of Aldridge $\&$ Becker (2003) suggests that between 6000 and 17000 children in England and Wales will be caring for a parent with mental illness at any one time. However, Aldridge \& Becker have also concluded that about 170000 children are caring for a parent with physical or mental illness and that it is likely that about a third of these parents have predominantly mental illnesses. On that basis about 55000 to 60000 children will be affected. Also, aggregated figures from a number of studies suggest that about 3 million children under the age of 16 are being significantly affected by a parent's mental or physical illness and therefore about 1 million can be expected to be affected by mental illness. The spread of these figures is probably an indication of the lack of knowledge about, as well as the previous serious neglect of, these children.

\section{The USA, the UK and Australia}

In the USA the National Co-morbidity Survey (Nicholson 1998, 1999) showed that 68\% of women with mental health disorders are parents, compared with $57 \%$ of men. Similar figures are reported in the UK (Richman 1976; Brown 1978; Oates 1997) and in Australia (McGrath 1999). Aggregated data suggest that having one mentally ill parent gives a child a $70 \%$ chance of developing at least minor adjustment problems by adolescence. With two mentally ill parents there is a $30-50 \%$ chance of becoming seriously mentally ill (Rubovits 1996). A child with an affectively ill parent has a $40 \%$ chance of developing affective disorder by age 20, compared with a $20-25 \%$ risk in the general population (Beardslee 1983).

\section{Other effects}

The UK Department of Health's training manual and reader on working with mentally ill parents and their children (Falcov 1998) includes evidence that the presence of mental illness in a parent has been shown to negatively affect the children's cognitive and language development, attention and concentration span, educational achievement and social, emotional and behavioural development.

Stuart (1998) has reported a 'befriending project' for children of parents with schizophrenia, in which $73 \%$ of the children reported serious distress resulting from their parent's illness - the main
Alan Cooklin is a consultant in family psychiatry at Camden and Islington NHS Foundation Trust, London, and an honorary senior lecturer at University College London, UK.

Correspondence Dr Alan Cooklin, The Family Project, 211 Kings Cross Road, London WC1X 9DN, UK. Email: alancooklin@famorg.com 
complaints being a sense of being ignored, pressure to be 'good', false maturity and a fear of family breakdown. Similar complaints were reported by Mackereth et al (1999), in which the young people interviewed reported a lack of explanation of their parent's disorder and a consequent sense of personal blame and responsibility.

\section{The hidden impact}

Weir \& Douglas (1999) reported that 'some children seem fine on the surface, until subsequent disclosure reveals that they have been experiencing neglect and abuse and have been living in fear for years, all the time wearing a mask'. This is backed up by Yule \& Williams (1990), who conclude that parents as well as other adults commonly underestimate the consequences of 'critical events' on children and the degree to which children think of, and are occupied with, what has happened. They write: '[it] seems that the assumption that "out of sight ... [means] ... out of mind" continues to predominate'. Dunn (1993) found that adults who had had a mentally ill parent when they were children retrospectively reported high levels of abuse and neglect, as well as isolation. This more candid reporting in adulthood of abusive experiences that were not disclosed during childhood suggests that there may be significant underreporting of abuse by children of mentally ill parents, even among those relatively few who are given an opportunity to talk about their experiences.

\section{Alternative caring adults}

A number of factors, particularly the presence of an alternative caring adult, can mitigate against these negative effects (Schachnow 1987). Quinton \& Rutter (1984) and Rutter $(1987,1990)$ identified a 'capacity to appraise' stressful situations (particularly through the availability of a warm, concerned, but relatively non-involved adult) as a significant protective factor. Cowling (1999) confirmed that the availability of one or more adults with whom the child can develop a supportive relationship is a key factor in a child's development of resilience in the face of parental mental illness. Falcov $(1999,2004)$ has further shown that the degree to which a child can develop a 'good' explanation (i.e. which is reasonably accurate, lowers the child's confusion and self-blame, and raises the child's self-esteem) of a parent's mental illness is associated with a lower level of 'caseness' on the Rutter B2 Scale (Rutter 1967). Thus, relatively small and appropriately timed interventions for children of a parent who has a mental illness can have a significant protective impact.

\section{Adoption}

At the extreme end of alternative care is adoption. A Finnish adoption study demonstrated that children of mothers with schizophrenia, who were subsequently adopted, had an incidence of schizophrenia similar to those who stayed with their mothers, when the sample was examined as a whole (Tienari 1985, 1994, 2004). However, when good-quality relationships and family environment were present, the incidence of schizophrenia reduced to that of the general population. This suggests that good relationships and family environment can have a strong protective function.

\section{Designing appropriate prophylactic interventions}

There is evidence that children can sometimes overcome the effects of extreme adversity, provided that they can understand what is happening to them (and as far as possible why) and that they have at least one reliable and impartial adult with whom they can affirm a more objective perception of events (Shachnow 1987; Quinton 1990). This is probably why the impact of any form of significant adversity on a child with poor or underdeveloped language skills can be more serious and more entrenched.

\section{Discussion and comprehension}

The first need of these children, therefore, is for a convincing and understandable explanation of what is happening to their parent, what is likely to happen and why, the likely impact on their own lives, and what part they can play in their parent's recovery. This takes priority over any suggested form of counselling or other therapy. Many children will actively - and often reasonably - oppose offers of counselling, which they may perceive as placing them in a similar category to their ill parent.

In keeping with studies by Rutter and others, evidence reported by Falcov (1999, 2004) suggests that appropriately discussing a parent's illness with a child or young person can have a significant protective effect. This is in line with the views of children and young people reported below. Possible reasons for this are outlined in Box 1.

Even explanation on its own, given over one or more discussions and provided that it can be shown to have been adequately understood by the child in a manner that is congruent to his or her developmental stage, can be a significant prophylactic intervention.

\section{The duty of intervening services}

It is incumbent on local health and social care services to ensure that each child of a parent with 
BOX 1 Positive effects of discussing a parent's mental illness with a child or young person

- An adequate explanation helps the child to objectify disordered behaviour in their parent and to free themselves from assuming inappropriate responsibility for their parent's disorder

- Discussion allows the child to test the reality of fears that they may automatically follow in their parent's footsteps

- Discussion acknowledges the child's competence countering the child's fear that professionals will perceive them to be following the parent's trajectory

- Two-way explanation, as defined in the training manual for Being Seen and Heard (Cooklin 2004), provides a medium in which the child can both identify and communicate their needs while maintaining a personal distance from the notion of being 'disturbed'

- Making society aware of 'young carers' as a social group mitigates the effects of stigma and social isolation

mental illness has one or more opportunities for detailed discussion of their parent's illness and this, if possible, needs to be linked with what the ill parent is willing and able to explain. If both parents are active in a child's care then the well parent should be given advice about why explanation is important and asked to participate in the discussion with the child.

\section{Shortfalls in the system}

Despite the government's initiative in the Every Child Matters programme, the needs of this group of children and young people appear to remain the responsibility of 'everyone and no-one'. This is partly because these children will often not present with overt and visible behavioural problems during the periods of their parent's illness. As a result they are unlikely to be known to the children and families sections of social services.

\section{A lack of training}

Many children in our project the Kidstime Workshops (Box 2) have reported that their social workers have tended to avoid much discussion of mental illness, claiming that it is not a subject that they themselves understand adequately or that has been addressed sufficiently in their training (Cooklin 2005). These children are rarely seen by child and adolescent mental health services (CAMHS), as they do not usually present with a level of symptomatology that would justify the use of their sparse resources. However, experienced
CAMHS workers may be able to offer a valuable training resource to staff working with the children. The size of their case-loads may be only part of the reason why many staff in community mental health teams are not addressing the need for explanation to the children. They also have been discouraged by worries about how to speak to children, uncertainty about what these children will understand and what in any case to explain about mental illness.

\section{Two-way explanations}

What is clear is that someone needs to explain the illness to the child and whoever takes this responsibility needs to consider in what context they will carry out this work. Although I have referred specifically to explaining to a child, it needs to be a two-way process. A presentation by a group of young carers that I attended recently stressed that one of the worst aspects of the experience was when the mental health services suddenly realised there was a problem and became involved. The young carers complained bitterly that even though they had often been managing the situation for months without help, no-one asked their advice, what they knew about their parent's illness or what made it better or worse. An example was a girl aged 8 who had been both monitoring and managing her mother's medication, without any of the services being aware of it.

\section{Forming a care network}

Inevitably, workers in mental health teams are the most likely to encounter the children, either at home, particularly when the parent is in the acute phase, or when the child visits their parent

\section{BOX 2 The Kidstime Workshops}

The Kidstime Workshops are monthly events for children and young people who have parents with mental illnesses - together with their parents. The workshops are run by a combination of mental health, social care and voluntary workers and last 2.5 hours after school. They begin with a short seminar for the children and parents together, in which some aspect of mental illness, or questions about it, are discussed. This is followed by separate groups for the children and for the parents. The children's group starts with games and warm-up exercises, then the children tell stories about family life, perhaps prompted by the seminar. They are helped to dramatise these stories and the resulting plays are filmed. The parents and children then gather as a single group to eat pizza and watch the filmed plays. Finally, there is a group discussion of what the children have produced and of issues raised in the parents' group. 
on a ward. It is therefore necessary for each team to form a network with the local Social Services, CAMHS and relevant voluntary bodies to develop a rapid-response strategy for children who may be affected by a parent's mental illness. Each group needs to be assured that someone will be talking to the child and to know who that person is. How to do it and what to say are outside the scope of this article. However, an ideal way to proceed is by setting up a local interagency group who may first need to discuss the kind of explanations they use and then practise - possibly in role-play - engaging young children in these explanations.

The training pack attached to the film Being Seen and Heard (Cooklin 2004) contains useful general advice about how to do this, as well as a manual - for those who find more prescriptive literature useful - about how to talk to children in such a situation. Boxes 3 and 4 contain information gained from discussions with children and young people about the effect on their lives of having a parent with mental illness, as well as their needs and wishes for intervention.

\section{Commentary}

This short article has attempted to highlight the plight of children of parents who have severe and enduring mental illness. I have argued that a child's right and need to understand their parent's mental illness should be met jointly by the mental health, social care and child and adolescent mental health services. In reality, this is highly problematic in the UK and as a result many children are wholly or partially neglected, receiving little or no explanation or, for that matter, any other service directed to their needs.

The problem is that these children and young people fall between the obvious responsibilities of all the relevant professionals. Mental health staff - often best placed to talk to the child because they are there at the time of or soon after a parent's crisis - will claim that they are illequipped in terms of both time and expertise to talk to children. In common with many professions, they seem almost to fear children. Social workers in the children and families sections of Social Services will make a similar claim, although for different reasons. They are often hard-pressed to respond to even the serious and obvious cases of child abuse in their locality and children with mentally ill parents are commonly not obvious. Such children often to try to hide their fears and concerns from outsiders, partly out of loyalty to their parent and partly through fear that they will be 'taken away'. Furthermore, many social workers will have had only minimal training in mental health and will feel ill-equipped to offer any explanation to a child.

BOX 3 Having a parent with a mental illness: the impact on children and their responses

\section{This information was extrapolated from discussions with children and young people over the past 5 years of the work in the Kidstime Workshops project.}

\section{Common complaints}

Children and young people complained particularly about losing the closeness with their ill parent, about fears for the parent's safety, about ambiguous expectations/demands (e.g. one parent's demands contradict those of the other parent, or one parent makes contradictory demands at different times) and about neglect and/or violence (verbal, physical and/or sexual).

\section{Fears}

They fear for the ill parent's safety, for the parents' future as a couple (if there are two parents), for the future of the family and about who will look after the child. They complain about contradictory expectations (i.e. that the child be 'grown up' and 'a carer' at home and a child at school), rejection, harassment and/or bullying by other children at school or in the neighbourhood.
Other impacts

Other common and well-documented impacts include invasion of the child's thinking and feelings by exposure to the parent's delusions and hallucinations, and isolation of the child through stigma and fear of rejection. The child's life will also be altered by: isolation of the family through stigma; lowered standard of living, with financial hardship; separation from parent/s and their usual daily routine; different and potentially confusing care patterns if looked after by others; separation from other family members (e.g. siblings if children cannot be cared for together); disruption of education, with underachievement and reduced life chances as a consequence.

\section{Responses}

Children and young people commonly respond to a parent's mental illness by:

- attempting to fill the care-taking space left by the parent by looking after parents and/ or siblings; as a result, the child may become dictatorial or bullying
- self-blame and taking undue responsibility for problems in the family or for the parent's illness

- confusion about how to interpret their ill parent's behaviour, particularly anger - is it caused by the illness or by something the child has done?

- increased compliance in response to the parent's unpredictability

- loyalty to the parent, through guilt and fear about the situation

- withdrawal and isolation

- depression, low self-esteem and/or a fatalistic acceptance of their situation

- attempts at disassociation from the problem, particularly if another sibling is 'taking control'

- violent and/or other self-destructive behaviour

- copying the parent's symptoms and/or behaviour, particularly in eating disorders. 
BOX 4 Children's needs and wishes in regards to having a parent with mental illness

This information was extrapolated from discussions with children and young people over 5 years of Kidstime Workshops.

\section{The needs and wishes expressed by the} children and young people

From a small study of 11- to 15-year-olds, living with a depressed parent, Garly et al (1997) found that the children particularly wanted to discuss the following four topics:

- understanding the illness, including their own concerns, ideas about the cause of the illness and access to information

- how to recognise the signs of an impending illness

- issues to do with hospitalisation

- advice about managing the illness, including coping with the effect on themselves as well as on their parent, perceptions of what is helpful to the parent and recommendations for other children whose parents are depressed.
This is in line with the wishes of the children and young people we interviewed, who wanted:

- to have a frank discussion about their parent's illness so they can think about the situation more objectively and to have their questions answered honestly and openly

- to know that there is an adult who will act as their advocate

- to know that their situation is not uncommon

- to have access to a place or a group where they can mix with other children and young people who have had similar experiences

- to be helped to develop their understanding of mental health problems and for any belief that they are responsible for the illness to be identified and challenged

- to discuss whether they could 'catch' the illness now or develop it later

- to understand what is and what is not acceptable behaviour from an adult
- to be helped to develop an understanding of how mental health services are organised and what treatment the parent is receiving

- to be helped to recognise when their parent is becoming ill, to understand the behavioural signs that show the onset of illness and to know how to access help

- to know that their knowledge and experience of their parent's illness will be listened to and taken into account in terms of care-planning

- to know that their contribution to the care of their parent has been recognised and respected

- to have daily life re-established

- for all the professionals concerned with both adults and children to be working together

- help and support with education, training and employment

- to have recognition and acknowledgment of any positive benefits of their situation.
Many assume that these children are the responsibility of the local CAMHS. These services, however, are often underresourced and anyway are required to give precedence to children with a defined disorder. In addition, many of these children will be highly averse to any suggestion that they require therapy or counselling, as they so closely associate this with 'following in their parent's footsteps'. The type of discussion outlined above allows professionals to relate to a child through his or her competence. Within such discussions a child may disclose many different kinds of need, which may be responded to in a way that is more respectful of the child's need to stay in control.

\section{References}

Aldridge J, Becker S (2003) Children Caring for Parents with Mental IIIness. Perspectives of Young Carers, Parents, and Professionals. Policy Press.

Beardslee R, Bemporad J, Keller M, et al (1983) Children of parents with major affective disorder. A review. American Journal of Psychiatry 140: 825-32

Brown GW, Harris T (1978) Social Origins of Depression. A Study of Psychiatric Disorders in Women. Tavistock.

Cooklin A, Balmer S, Hart D, et al (2004) Being Seen and Heard. The Needs of Children of Parents with Mental IIIness (training film). Gaskell.

Cooklin A (2005) Young carers, young victim or young survivors? Impacts on, and responses of, children of parents with mental illness. In Partners in Care Training Resource (ed M McClure). Royal College of Psychiatrists.

Cowling V (1999) Children of Parents with Mental IIIness. ACER Press.

Dunn B (1993) Growing up with a psychotic mother. A retrospective study. American Journal of Orthopsychiatry 63: 177-89.
Falcov A (1996) Department of Health Study of Working Together "Part 8" Reports. Fatal Child Abuse and Parental Psychiatric Disorder. ACPC Series Report No. 1. Department of Health.

Falcov A (1998) Crossing Bridges. Training Resources for Working with Mentally III Parents and their Children. Reader for Managers, Practitioners and Trainers. Pavilion Publishing.

Falcov A (1999) Addressing family needs when a parent is mentally ill. In Approaches to the Assessment of Need in Children's Services (eds H Wood, W Rose): pp 235-60. Jessica Kingsley.

Falcov A (2004) Talking with children whose parents experience mental illness. In Children of Parents with Mental IIIness. Personal and Clinical Perspectives (2nd edn) (ed V Cowling): pp 41-56. Acer Press.

Mackereth S, Göpfert M, Harrison P, et al (1999) Keeping the Family in Mind. Participative Research into Mental III-Health and How it Affects the Whole Family. North Mersey Community NHS Trust, Barnado's and Save the Children.

McGrath J, Hearle J, Jenner L, et al (1999) The fertility and fecundity of patients with psychoses. Acta Psychiatrica Scandinavica 99: 441-6.

Nicholson J, Sweeney EM, Geller JL (1998) Mothers with mental illness I. The competing demands of parenting and living with mental illness. Psychiatric Services 49: 635-42.

Nicholson J, Nason MW, Calabresi A0, et al (1999) Fathers with severe mental illness. Characteristics and comparisons. American Journal of Orthopsychiatry 69: 134-41

Oates M (1997) Patients as parents. The risk to children. British Journal of Psychiatry 170 (suppl. 32): 22-7.

Quinton D, Rutter M (1984) Parents with children in care. 1 Current circumstances and parents, 2 Intergenerational continuities. Journal of Child Psychology and Psychiatry 25: 211-31.

Quinton D, Rutter M, Gulliver L (1990) Continuities in psychiatric disorders from childhood to adulthood in the children of psychiatric patients. In Straight and Devious Pathways from Childhood to Adulthood (eds L Robins, M Rutter): pp 12-3. Cambridge University Press.

Richman N (1976) Depression in mothers of preschool children. Journal of Child Psychology and Psychiatry 17: 75-8.

\begin{tabular}{|c|c|c|c|c|}
\hline \multicolumn{5}{|c|}{ MCQ answers } \\
\hline 1 & 2 & 3 & 4 & 5 \\
\hline af & af & af & af & a f \\
\hline$b f$ & $b f$ & $b f$ & $b f$ & $b f$ \\
\hline$c f$ & $c f$ & $c f$ & $c t$ & $c f$ \\
\hline$d t$ & $d t$ & $d f$ & $d f$ & $d f$ \\
\hline ef & ef & $e t$ & ef & et \\
\hline
\end{tabular}


Rubovits P (1996) Project CHILD. An Intervention Programme for Psychotic Mothers and their Young Children. In Parental Psychiatric Disorder. Distressed Parents and their Families (eds M Göpfert, J Webster, MV Seeman): pp 161-9. Cambridge University Press.

Rutter M (1967) A children's behaviour questionnaire for completion by teachers: preliminary findings. Journal of Child Psychology and Psychiatry 8: $1-11$

Rutter M (1990) Psychosocial resilience and protective mechanisms. In Risk and Protective Factors in the Development of Psychopathology (eds J Rolf, AS Masten, D Cicchetti et al): pp 181-214. Cambridge University Press.

Shachnow J (1987) Preventive intervention with children of hospitalised psychiatric patients. American Journal of Orthopsychiatry 57: 66-77.

Stuart A (1998) The Willow Scheme. In National Handbook of Young Carer's Projects (eds J Aldridge, S Becker). Young Carer's Association.
Tienari P, Sorri A, Lahti I, et al (1985) Interaction of genetic and psychosocial factors in schizophrenia. Acta Psychiatrica Supplement, 319: 19-30.

Tienari P, Wynne LC, Moring J, et al (1994) The Finnish adoptive family study of schizophrenia. Implications for family research. British Journal of Psychiatry 164 (suppl 23): 20-6.

Tienari P, Wynne LC, Sorri A, et al (2004) Genotype-environment interaction in schizophrenia-spectrum disorder. Long-term followup study of Finnish adoptees. British Journal of Psychiatry 184: 216-22

Weir A, Douglas A (1999) Child Protection and Adult Mental Health. Conflict of Interest? Butterworth Heinemann.

Yule W, Williams RM (1990) Post-traumatic stress reactions in children. Journal of Traumatic Stress 3: 279-95.

\section{MCOs}

1 Mental illness in parents has the following effects on their children:

a a $60 \%$ incidence of schizophrenia or bipolar disorder

$\mathrm{b}$ a high incidence of anti-social behaviour

c a $70 \%$ increase in eating disorders

d high levels of adjustment disorders and educational underachievement

e improved social skills with peers.

2 Children of mothers with schizophrenia who were adopted during the first 18 months of life manifested:

a a much lower overall incidence of schizophrenia than the general population

b a higher incidence of schizophrenia than those brought up by their biological mothers

c a much lower overall incidence of schizophrenia than those brought up by their biological mothers $d$ an equivalent incidence of schizophrenia to that of the general population if their adoptive families were in the optimum band

e many additional adjustment disorders.

3 Children affected by parental mental illness represent:

a only those recognised as young carers

b 65000 children in the UK

c only those who are the children of parents who have received in-patient psychiatric treatment

d mainly the children of parents with borderline personality disorder

e up to one million children throughout the UK

4 Children of parents with a mental illness will nearly all (if asked) express a wish for: a counselling and /or therapy for themselves

b family therapy with their ill parent

c an understandable explanation of their parent's illness d foster care

e in-patient treatment for their ill parent.

5 Under UK legislation, the responsibility to ensure that the child of an ill parent has an opportunity to discuss the illness with a neutral adult rests with:

a the clinically responsible consultant psychiatrist

b the children, schools and families social worker

c the local child and adolescent mental health service

d a local voluntary body, such as a young carers' project

e all of the above. 